\title{
Outcomes of Automated Auditory Evoked Potential Performed in Different Settings and the Factors Associated with Referred Cases
}

\author{
Daniela Polo Camargo da Silva ${ }^{1}$ Georgea Espíndola Ribeiro ${ }^{1}$ Gustavo Leão Castilho ${ }^{1}$ \\ Jair Cortez Mantovani ${ }^{1}$ \\ ${ }^{1}$ Department of Ophthalmology, Otorhinolaringology and Head and \\ Neck Surgery, Faculdade de Medicina de Botucatu, Universidade \\ Estadual Paulista (UNESP), Botucatu, SP, Brasil \\ Address for correspondence Daniela Polo Camargo da Silva, PhD, \\ Departamento de Oftalmologia, Otorrinolaringologia e Cirgurgia de \\ Cabeça e Pescoço, Faculdade de Medicina de Botucatu, Distrito de \\ Rubião Júnior s/n, Botucatu, SP, 18618-970, Brazil \\ Int Arch Otorhinolaryngol 2018;22:342-347. \\ (e-mail: daniela-polo@uol.com.br).
}

\begin{abstract}
Introduction For the population with risk factors for hearing loss, the first option to assess the hearing status is the performance of the automated brainstem auditory evoked potential (BAEP) test because of its efficacy in identifying retrocochlear hearing loss.

Objective To verify the outcomes of automated BAEP performed in different settings as well as the factors associated with the prevalence of hearing impairment.

Methods Cross-sectional study conducted from October of 2014 to May of 2015. The sample consisted of 161 infants with at least one risk factor for hearing loss who underwent automated BAEP during the hospital stay or at the outpatient clinic. After 30 days, the altered cases were referred for BAEP diagnosis.

Results One hundred and thirty-eight infants (86\%) had a result of "pass" and 23 $(14 \%)$ of "failure" in the automated BAEP. There was no statistically significant difference in the rate of "referred" results between examinations performed in different settings. The infants' ages did not influence the number of abnormal cases.

Keywords

- neonatal screening

- hearing loss

- infant

- risk index

- electrophysiology All of the 23 infants who presented a "referred" result in the automated BAEP, unilateral or bilateral, were sent for BAEP diagnosis, and out of these, $9(39 \%)$ remained with at least some degree of alteration. The average age of diagnosis was 2.7 months. Conclusion The results of the automated BAEP were similar when performed during hospitalization or after discharge. Neither the age at the examination nor the gender of the patient influenced the prevalence of hearing loss.
\end{abstract}

\section{Introduction}

The integrity of the auditory pathway is important for the child to acquire oral language. On the other hand, auditory deprivation, especially in the first year, can lead to several cognitive impairments in the child's psychosocial behavior. ${ }^{1-3}$ Therefore, it is important to perform the neonatal hearing screening as soon as possible so that the diagnosis of hearing loss can be completed until the third month of life and the beginning of the intervention takes place before the sixth month of life. ${ }^{1,4}$
Usually, this screening is based on electroacoustic and electrophysiological measures of hearing, such as the otoacoustic emissions (OAE) and the brainstem auditory evoked potential (BAEP).$^{5-7}$ Both methods evaluate objectively the integrity of the auditory pathway and the equipment used is automated; the professional's participation is restricted to adjusting the conditions of records and interpreting the validity of the results obtained. ${ }^{8}$

Currently, in infants with risk indicators for hearing loss, it is recommended that the BAEP is performed directly on received

April 23, 2017

accepted

September 3, 2017

published online

October 25, 2017
DOI https://doi.org/

10.1055/s-0037-1607334. ISSN 1809-9777.
Copyright (e 2018 by Thieme Revinter

Publicações Ltda, Rio de Janeiro, Brazil
License terms

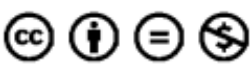


automated equipment because it is a simple, fast, noninvasive and effective method to identify retrocochlear hearing loss. ${ }^{4,9}$ Another advantage to be highlighted is that this type of BAEP is less influenced by changes in the external ear, such as vernix, and otitis in the middle ear besides being less influenced by any noise in the test room. ${ }^{10}$ It should also be considered that with the reduction of false-positives by automated BAEP, the family's anxiety is reduced, unnecessary referrals for diagnosis are prevented and the economic costs of hearing evaluation are restricted. ${ }^{11,12}$

One of the limitations of the automated BAEP is that there is a greater number of failures when evaluating preterm infants before 34 weeks of life. ${ }^{13,14}$ Therefore, if the evaluation occurs before this period, the failures must be retested to avoid the false diagnosis of hearing impairment caused by the natural process of auditory maturation.

Another fact to be considered is that the tests used for the pediatric audiological diagnosis are not always performed in the same environment. Usually, the initial evaluation is performed at the nursery or at intensive care units (ICUs).

The literature shows that infants admitted in ICUs present a higher rate of hearing impairment when compared with the general pediatric population. ${ }^{15}$ However, it is yet unclear if these alterations are due to the attributes of the exam setting or the intrinsic characteristics of the infant. Because of the extremely distinct characteristics of the exam settings, local circumstances can lead to variations in the results obtained. ${ }^{11}$

This study aimed to verify the outcomes of automated BAEP performed in different sites, as well as the factors associated with the prevalence of hearing impairment.

\section{Materials and Methods}

This research was approved by the Research Ethics Committee of the local institution (protocol 402/08).

A cross-sectional study was performed at a public hospital between October of 2014 and May of 2015.

Inclusion criteria: infants with risk indicator for hearing loss; similar clinical conditions among neonates evaluated during the period of hospitalization and at the outpatient clinic; automated BAEP performed in the universal neonatal hearing screening program; an informed consent term was signed by their parents.

Exclusion criteria: excluded from the study were patients with any alteration of the middle ear identified by the ENT doctor before the tests.

The first test was the automated BAEP, which was performed in two different settings: at the intensive care unit (ICU), when the infant was hospitalized, and at the outpatient clinic. Thirty days after failure in the automated BAEP performed in an outpatient setting, a conventional BAEP was performed.

\section{Automated BAEP Technical Specifications}

The AccuScreen (Otometrics, Taastrup, Denmark) equipment was used with the infant in a natural sleep.

The abrasive substance Nuprep (Weaver and Company, Aurora, CO, USA) was used to clean the skin and the Neuroline (Ambu, Ballerup, Denmark) surface electrodes were fixed in the front $(\mathrm{Fz})$, occipital $(\mathrm{Oz})$ and zygomatic regions. The impedance of the electrodes was always kept below 5 Kohms. Data was shown in an 18-ms window post-stimulus, applying a binomial statistical evaluation algorithm over the sinuous pattern signal, which offered a confidence level of $>99.5 \%$ for the response. The waveform generated from the brainstem was compared with a template derived from normally hearing infants. The equipment screen showed a graph that indicated test progress, EEG level and BAEP detection probability. The equipment had a builtin rejection device for myogenetic, electrical and environmental noise interference that stopped the screening when testing conditions would preclude adequate testing. The stimulus used was the click, at an intensity level of $35 \mathrm{dBnHL}$ and a rate of 78-82 clicks per second (randomized). When the ideal parameters established by the equipment software were reached, there was a result of "pass," and if not, there was a result of "referred"

\section{Conventional BAEP Technical Specifications}

The EP15 Eclipse (Interacoustics, Middelfart Denmark) equipment was used in a silent room with the infant in a natural sleep.

The abrasive substance Nuprep was used to clean the skin, and the surface electrodes (Neuroline) were fixed in different points; the active and ground were fixed to the forehead (Fz, Fpz) and the reference in the regions of the mastoid (M1 and M2). The stimulus was presented through an insert earphone ER 3A (Interacoustics A/S, Assens, Denmark) with monaural stimulation with filtered clicks (high pass band filter of $100 \mathrm{~Hz}$ and low pass filter of $2000 \mathrm{~Hz}$ ), duration of $100 \mu$ s and rarefied polarity. A total of 1,024 clicks with analysis time of 20 milliseconds were provided and repeated to confirm the reproducibility of the waves. The impedance of the electrodes was always kept below 3 Kohms. The stimulus presentation rate was 20.1 clicks per second.

The initial intensity of the acoustic stimulus was $80 \mathrm{dBnHL}$ for the neural integrity investigation, and for electrophysiological threshold investigation, the intensity was decreased in steps of $20 \mathrm{dBnHL}$ until the confirmation of the last intensity in which the $V$ wave was visualized. In the absence of response, the intensity was increased in steps of $10 \mathrm{dBnHL}$ until the $\mathrm{V}$ wave was visualized, never exceeding the intensity of $100 \mathrm{dBnHL}$.

Normal hearing was determined by the presence of response on the conventional BAEP at an intensity level $\leq 30 \mathrm{dBnHL}$. The degree of hearing loss was categorized according to the threshold value of the BAEP threshold: mild (40 and $50 \mathrm{dBnHL}$ ), moderate (60 and $70 \mathrm{dBnHL}$ ), severe (80 and $90 \mathrm{dBnHL}$ ) and profound (>90 dBnHL). ${ }^{16}$

\section{Statistical Analysis}

Descriptive statistics were performed with frequency and percentage for categorical variables, and mean, minimum and maximum for continuous variables.

The analysis of the prevalence of abnormal results in the automated BAEP by site, age at examination and gender was performed by multiple Cox regression. Relationships were considered statistically significant if $p<0.05$. The software used was the SPSS version 21.0 (IBM Corp., Armonk, NY, USA). 
Table 1 Sample characterization

\begin{tabular}{|l|l|l|}
\hline Variables & ICU $(\boldsymbol{n}=60)$ & $\begin{array}{l}\text { Outpatient } \\
\text { clinic }(\boldsymbol{n}=101)\end{array}$ \\
\hline Female/Male & $26(43 \%) / 34(56 \%)$ & $47(46 \%) / 54(53 \%)$ \\
\hline $\begin{array}{l}\text { Gestational } \\
\text { age }^{\mathrm{a}}\end{array}$ & $31(26-42)$ & $36(25-42)$ \\
\hline $\begin{array}{l}\text { Birth weight } \\
\text { (grams) }^{\mathrm{a}}\end{array}$ & $1,578(700-3,580)$ & $2,567(760-4,345)$ \\
\hline
\end{tabular}

Abbreviation: ICU, intensive care unit.

a Average, minimum and maximum values.

\section{Results}

A total of 161 infants of both genders met the study inclusion criteria, and automated BAEP tests were recorded in 322 ears. The characterization of the sample is shown in - Table 1 and - Fig. 1

The results of neonatal hearing screening in infants with risk indicators using automated BAEP showed that 138 infants (86\%) had a "pass" result, while 23 of them (14\%) had a "referred" result. However, this evaluation was not done in the same setting; 60 tests were performed in the ICU during hospitalization and 101 were performed in the outpatient clinic after discharge. Nervertheless, no statistically significant difference was observed between the "referred" rates when comparing the results of the automated BAEP performed at different locations (-Table 2). It is emphasized that all the infants with a "referred" result in the automated BAEP performed at the ICU were assigned to the outpatient setting for a conventional BAEP.

When analyzing the age at which the infants underwent the automated BAEP, 24 (15\%) were $\leq 34$ weeks and 137 $(85 \%) \geq 35$ weeks, but the age at the time of the examination did not influence the increase in the rates of "referred" in this test ( $\mathbf{- T a b l e ~} \mathbf{2}$ ).

Regarding the gender, no statistical significance was found in relation to the increased prevalence of abnormal results in the automated BAEP ( $\mathbf{- T a b l e ~} \mathbf{2}$ ).

The 23 infants who presented the "referred" result in the automated BAEP - unilateral or bilateral - were referred to
Table 2 Prevalence ratio of abnormal automated BAEP by location, age and gender

\begin{tabular}{|c|c|c|c|c|}
\hline & PR & \multicolumn{2}{|c|}{$\mathrm{Cl} 95 \%$} & $p$ \\
\hline \multicolumn{5}{|c|}{ Abnormal automated BAEP - Right ear } \\
\hline \multicolumn{5}{|l|}{ Variable } \\
\hline Hospitalization & 1.21 & 0.40 & 3.63 & 0.740 \\
\hline $\begin{array}{l}\text { Age at the time of } \\
\text { the test }<34 \text { weeks }\end{array}$ & 1.00 & 0.94 & 1.06 & 0.915 \\
\hline \multirow[t]{2}{*}{ Male } & 1.34 & 0.55 & 3.23 & 0.521 \\
\hline & PR & \multicolumn{2}{|l|}{$\mathrm{Cl} 95 \%$} & $p$ \\
\hline \multicolumn{5}{|c|}{ Abnormal automated BAEP - Left ear } \\
\hline \multicolumn{5}{|l|}{ Variable } \\
\hline Hospitalization & 1.07 & 0.29 & 3.98 & 0.925 \\
\hline $\begin{array}{l}\text { Age at the time of } \\
\text { the test }<34 \text { weeks }\end{array}$ & 1.03 & 0.97 & 1.09 & 0.378 \\
\hline \multirow[t]{2}{*}{ Male } & 1.11 & 0.41 & 3.01 & 0.834 \\
\hline & PR & \multicolumn{2}{|l|}{$\mathrm{Cl95 \%}$} & $p$ \\
\hline \multicolumn{5}{|c|}{ Abnormal automated BAEP - uni or bilateral } \\
\hline \multicolumn{5}{|l|}{ Variable } \\
\hline Hospitalization & 1.13 & 0.38 & 3.31 & 0.829 \\
\hline $\begin{array}{l}\text { Age at the time of } \\
\text { the test }<34 \text { weeks }\end{array}$ & 1.01 & 0.95 & 1.06 & 0.876 \\
\hline Male & 1.56 & 0.66 & 3.68 & 0.312 \\
\hline
\end{tabular}

Abbreviations: BAEP, brainstem auditory evoked potential; Cl, correlation index; PR, prevalence ratio.

the conventional BAEP. Nine of them (39\%) remained with at least some degree of alteration while $14(61 \%)$ had responses within normal patterns bilaterally. The results of abnormal conventional BAEP per ear are shown in -Table 3.

Out of the nine infants diagnosed with abnormal BAEP, three had more than one cumulative risk indicator, and the most frequent was prolonged stay in neonatal ICUs ( - Table 4).

None of these infants diagnosed with hearing loss came from the ICU and the mean age at diagnosis was 2.7 months.

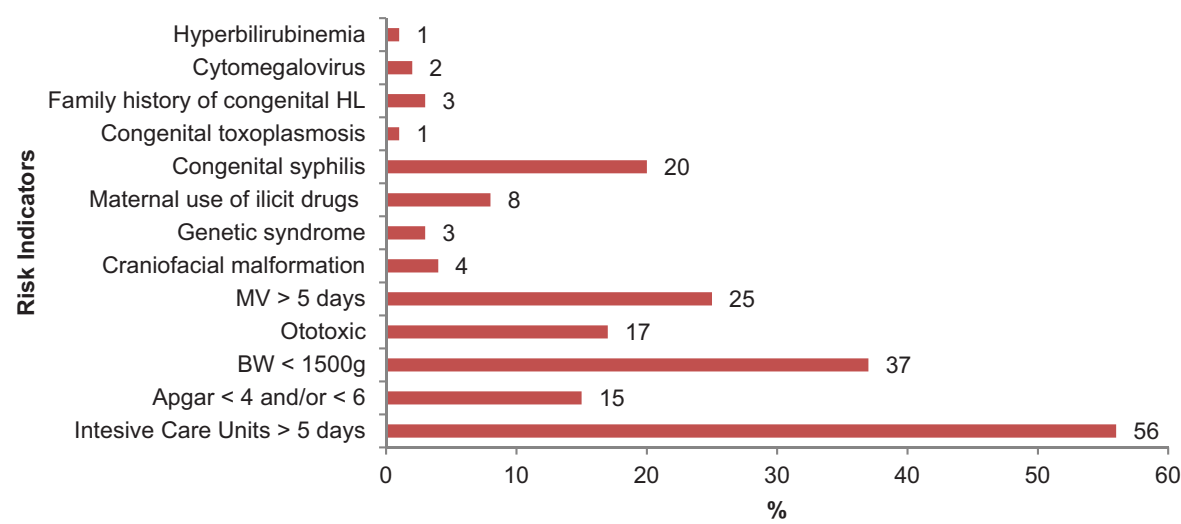

Fig. 1 Frequency (\%) of risk indicators in all infants evaluated in the study. Abbreviations: BW, birth weight; HL hearing loss; MV, mechanical ventilation. 
Table 3 Distribution of abnormal conventional BAEP per ear

\begin{tabular}{|l|l|l|l|}
\hline BAEP & RE & LE & Total \\
\hline Mild $(40-50 \mathrm{dBnHL})$ & 3 & 1 & 4 \\
\hline Moderate $(60-70 \mathrm{dBnHL})$ & 2 & 3 & 5 \\
\hline Severe $(80-90 \mathrm{dBnHL})$ & 0 & 0 & 0 \\
\hline Profound $(>90 \mathrm{dBnHL})$ & 3 & 3 & 6 \\
\hline Total & 8 & 7 & 15 \\
\hline
\end{tabular}

Abbreviations: BAEP, Brainstem auditory evoked potential; dBnHL, decibel normal hearing level; LE, left ear; RE, right ear.

\section{Discussion}

Decreasing the number of false-positive in the neonatal, hearing screening is a constant challenge, especially because we deal with individuals in the process of language acquisition and development. The early diagnosis aims to reduce the consequences that hearing loss can bring, and the more reliable the result is, the more effective the hearing screening program becomes. ${ }^{17,18}$

Studies show that neonatal hearing screening performed using OAE presents a high false-positive rate when compared with automated BAEP. Thus, it is emphasized that the retest should be done with automated BAEP in an attempt to reduce the number of cases referred for diagnosis. ${ }^{18,19}$

In addition, the use of automated BAEP as an initial screening tool, which is recommended for infants with risk indicators for hearing loss, allows investigation of the auditory pathway. ${ }^{20-22}$ Based on this, only infants with risk indicators for hearing loss were included in this study, without performing OAE.

The automated BAEP offers two types of response, "pass" or "referred," and is performed at a low intensity; however, altered results may include infants with diferent degrees of hearing loss but still with some ability to listen. Therefore, the 23 cases with abnormal results in the automated BAEP were sent to the conventional BAEP, which made possible to verify both the integrity of the auditory pathway and to estimate the electrophysiological threshold. However, this type of examination requires a greater amount of time to be performed and an experienced professional to analyze the response, especially when performed in premature infants. ${ }^{23}$

Although the presence of risk indicators for hearing loss and prematurity increase the chances of a "referred" result in hearing screening, this study showed that out of the 161 infants screened, $86 \%$ of them had a satisfactory result already in the first assessment, independent of the location or whether the test was performed during hospitalization or after hospital discharge. These results are in agreement with other studies that show the effectiveness of the automated BAEP in the reduction of falsepositive results when compared with the OAE method. ${ }^{19,24}$

It must also be highlighted that in this study the cases that were screened during the period of ICU stay showed an abnormality rate of only $15 \%$. This shows the effectiveness of this examination in noisy environments, such as hospitalization units, as well as the non-viability of the OAE test. ${ }^{24}$

To assess the effects of age on automated BAEP, the age of the participants at the time of examination was considered as a way of not impairing the analysis of the auditory evaluation results.

According to the Joint Committee on Infant Hearing (JCIH), hearing screening in neonates who are hospitalized should be performed before 44 weeks of age, but in this study two infants were evaluated after the recommended age because they were not able to undergo the test before this period. However, Jacobson et al $(1990)^{13}$ proposed that screening should be performed from the 34th week on and in this study, 13 infants were evaluated prior to this recommendation because they had already been discharged from the hospital.

Nevertheless, when the age effect analysis was performed it was observed that there was no increase in the number of "referred" results in the automated BAEP, which shows that although some infants were evaluated out of the ideal period or were born premature, this difference did not interfere with the test results.

Studies indicate a higher prevalence of abnormal results in males when hearing screening is performed by OAE, but in this study the abnormal results were similar between the genders and this is attributed to the fact that this screening was performed only by automated BAEP. ${ }^{25}$

Table 4 Risk indicators for hearing loss in infants with abnormal conventional BAEP

\begin{tabular}{|l|l|l|l|l|l|l|l|l|}
\hline Patient & $\begin{array}{l}\text { Low } \\
\text { Apgar }\end{array}$ & $\begin{array}{l}\text { BW } \\
<1,500 \mathrm{~g}\end{array}$ & $\begin{array}{l}\text { ICU } \\
>\mathbf{5} \text { days }\end{array}$ & $\begin{array}{l}\text { MV } \\
>5 \text { days }\end{array}$ & Ototoxic & $\begin{array}{l}\text { Genetic } \\
\text { syndrome }\end{array}$ & $\begin{array}{l}\text { Maternal use } \\
\text { of ilicit drugs }\end{array}$ & $\begin{array}{l}\text { Craniofacial } \\
\text { malformation }\end{array}$ \\
\hline 1 & & & & & & & + & \\
\hline 2 & & & + & & & & & \\
\hline 3 & & & + & & & & & \\
\hline 4 & & + & + & & & + & & \\
\hline 5 & & & & & & & & \\
\hline 6 & & & + & + & & & & \\
\hline 7 & + & & + & & + & & & \\
\hline 8 & & & & & & + & & \\
\hline 9 & & & & & & & & \\
\hline
\end{tabular}

Abbreviations: BAEP, braistem auditory evoked potential; BW, Birth weight; ICU, intensive care unit; MV, mechanical ventilation. 
Of the 161 infants screened, 23 (14\%) obtained a "referred" result in the automated BAEP and were considered with a probable diagnosis of hearing loss. However, only nine (5\%) confirmed hearing loss - unilateral or bilateral - of varying degrees, showing a false-positive index of $8 \%$ when conventional BAEP was performed. The initial failure can be attributed to the fact that these tests were performed only in infants with risk indicators for hearing loss. Although the influence of these indicators, not evaluated in this study, may have interfered with the negative outcome of the screening, the results of this study were better than those reported by other authors, who found a false-positive index of $15 \%$ when screening was performed by automated BAEP in neonates at risk. ${ }^{26}$

In addition, the improvement of BAEP results has been described in cases of neonates at risk, such as perinatal asphyxia, and in other cases of transient ischemia, 27,28 emphasizing that the interference of the risk indicator for hearing loss cannot be forgotten and the analysis of the results should be cautious. Other authors also emphasize that neural conduction is influenced by maturation and the diagnostic conclusion depends on this factor. ${ }^{29}$

This study showed the average age of diagnosis to be 2.7 months, in agreement recent study by Li et al, ${ }^{18}$ whose mean was similar to that of neonates coming from the neonatal ICU and the nursery.

Finally, the data from this study demonstrate that performing two-stage hearing screening in neonates at risk for hearing loss, the initial one by automated BAEP and the final by conventional BAEP, allowed the accuracy of the early identification of hearing loss, favoring the referral for complementary evaluations through behavioral and electrophysiological tests by specific frequency.

\section{Conclusion}

The results of the automated BAEP were similar when performed during hospitalization or after discharge. The patient's age at the examination as well as the gender did not influence the prevalence of hearing loss.

\section{References}

1 Yoshinaga-Itano C, Wiggin M. A look into the crystal ball for children who are deaf or hard of hearing: needs, opportunities, and challenges. Semin Speech Lang 2016;37(04):252-258

2 Lederberg AR, Schick B, Spencer PE. Language and literacy development of deaf and hard-of-hearing children: successes and challenges. Dev Psychol 2013;49(01):15-30

3 Drion B. Newborn hearing screening and deafness care in deaf families: Be careful of tactlessness!. Arch Pediatr 2016;23(07): 773-774

4 American Academy of Pediatrics, Joint Committee on Infant Hearing. Year 2007 position statement: Principles and guidelines for early hearing detection and intervention programs. Pediatrics 2007;120(04):898-921

5 Stürzebecher E, Cebulla M. Automated auditory response detection: Improvement of the statistical test strategy. Int J Audiol 2013;52(12):861-864

6 de Kock T, Swanepoel D, Hall JW III. Newborn hearing screening at a community-based obstetric unit: Screening and diagnostic outcomes. Int J Pediatr Otorhinolaryngol 2016;84:124-131
7 Pimperton H, Blythe H, Kreppner J, et al. The impact of universal newborn hearing screening on long-term literacy outcomes: a prospective cohort study. Arch Dis Child 2016;101(01):9-15

8 Cebulla M, Stürzebecher E. Automated auditory response detection: Further improvement of the statistical test strategy by using progressive test steps of iteration. Int J Audiol 2015;54(08): 568-572

9 Lewis DR, Marone SAM, Mendes BCA, et al. Multiprofessional committee on auditory health: COMUSA. Rev Bras Otorrinolaringol 2010;76(01):121-128

10 Angrisani RMG, Suzuki MR, Pifaia GR, et al. Automatic ABR in newborns risk: study of sensitivity and specificity. Rev CEFAC 2012;14(02):223-233

11 Benito-Orejas JI, Ramírez B, Morais D, et al. Comparison of twostep transient evoked otoacoustic emissions (TEOAE) and automated auditory brainstem response (AABR) for universal newborn hearing screening programs. Int J Pediatr Otorhinolaryngol 2008;72(08):1193-1201

12 Faistauer M, Augusto TAM, Floriano M, et al. Implementation of a program of universal newborn hearing screening in a university hospital in a city in south Brazil: preliminary results. Rev AMRIGS 2012;56(01):22-55

13 Jacobson JT, Jacobson CA, Spahr RC. Automated and conventional ABR screening techniques in high-risk infants. J Am Acad Audiol 1990;1(04):187-195

14 van Straaten HL, Tibosch CH, Dorrepaal C, et al. Efficacy of automated auditory brainstem response hearing screening in very preterm newborns. J Pediatr 2001;138(05):674-678

15 Qi B, En H, Huang L. The review of newborn hearing screening program in neonatal intensive care unit. Lin Chung Er Bi Yan Hou Tou Jing Wai Ke Za Zhi 2015;29(23):2103-2106

16 Xu ZM, Cheng WX, Yang XL. Performance of two hearing screening protocols in NICU in Shanghai. Int J Pediatr Otorhinolaryngol 2011;75(10):1225-1229

17 Conti G, Gallus R, Fetoni AR, et al. Early definition of type, degree and audiogram shape in childhood hearing impairment. Acta Otorhinolaryngol Ital 2016;36(01):21-28

18 Li PC, Chen WI, Huang CM, et al. Comparison of newborn hearing screening in well-baby nursery and NICU: a study applied to reduce referral rate in NICU. PLoS One 2016;11 (03): 0152028

19 van Dyk M, Swanepoel W, Hall JW III. Outcomes with OAE and AABR screening in the first $48 \mathrm{~h}$-Implications for newborn hearing screening in developing countries. Int J Pediatr Otorhinolaryngol 2015;79(07):1034-1040

20 Berg AL, Spitzer JB, Towers HM, et al. Newborn hearing screening in the NICU: profile of failed auditory brainstem response/passed otoacoustic emission. Pediatrics 2005;116(04):933-938

21 Suppiej A, Rizzardi E, Zanardo V, et al. Reliability of hearing screening in high-risk neonates: comparative study of otoacoustic emission, automated and conventional auditory brainstem response. Clin Neurophysiol 2007;118(04):869-876

22 Smets K, Verrue N, Dhooge I. Implementation and results of bedside hearing screening with automated auditory brainstem response in the neonatal intensive care unit. Acta Paediatr 2012; 101(09):e392-e398

23 Baldwin M, Watkin P. Predicting the degree of hearing loss using click auditory brainstem response in babies referred from newborn hearing screening. Ear Hear 2013;34(03):361-369

24 McGurgan IJ, Patil N. Neonatal hearing screening of high-risk infants using automated auditory brainstem response: a retrospective analysis of referral rates. Ir J Med Sci 2014;183(03): 405-410

25 Berninger E, Westling B. Outcome of a universal newborn hearingscreening programme based on multiple transient-evoked otoacoustic emissions and clinical brainstem response audiometry. Acta Otolaryngol 2011;131(07):728-739 
26 van Straaten HL, Hille ET, Kok JH, et al. Implementation of a nation-wide automated auditory brainstem response hearing screening programme in neonatal intensive care units. Acta Paediatr 2003;92(03):332-338

27 Jiang ZD, Ping LL, Wilkinson AR. Functional abnormality of the auditory brainstem in high-risk late preterm infants. Clin Neurophysiol 2012;123(05):993-1001
28 Jiang ZD. A longitudinal study of brainstem auditory response from birth to late term in late preterm babies and abnormal findings in high-risk babies. J Perinat Med 2015;43(06):769-776

29 Silva Dd, Lopez P, Mantovani JC. Auditory brainstem response in term and preterm infants with neonatal complications: the importance of the sequential evaluation. Int Arch Otorhinolaryngol 2015;19(02):161-165 